\title{
EL CAFE Y LA POLITICA COLONIAL EN PUERTO RICO A FINES DEL SIGLO XIX: DOMINACION MERCANTIL EN EL PUERTO DE ARECIBO *
}

ASTRID CUBANO

Universidad de Puerto Rico

Durante el siglo xIx, Puerto Rico fue una posesión colonial de España en forma estable. Es de interés recurrente entre los historiadores ponderar los elementos que establecieron esa relación colonial sobre una base firme. ¿Qué mantuvo unidas dos nacionalidades en un acuerdo que concedía acceso desigual al poder político? ¿Cuál fue la base del pacto colonial en el Puerto Rico del siglo $X I X$ ?

Estas preguntas se vuelven más intrigantes todavía si consideramos que Cuba, la otra posesión española en el Caribe, siguió un patrón de comportamiento político totalmente diferente. Esto es todavía más cierto hacia fines de siglo, cuando el movimiento independentista cubano alcanzó proporciones nacionales. Una apreciación integral de la opinión pública coetánea en Puerto Rico demuestra que los terratenientes tendían a aliarse con España y no tenían intención alguna de sustituir el gobierno de Madrid por la independencia'.

La situación política fue el resultado del consenso entre una gran cantidad de los propietarios (terratenientes, comerciantes y profesionales). Resulta útil el enfoque comparativo de Rafael María de Labra en su análisis sobre la cuestión colonial española. Al argumentar a favor de las reformas políticas para Puerto Rico en 1870, Labra subrayó la naturaleza dispersa de la propiedad como prueba de las grandes posibilidades de éxito de un régimen democrático liberal en la más pequeña de las dos colonias. Había en Puerto Rico un total de 55.105 propietarios agrícolas. Cuba, con una población de 1.359.238, doble de la de Puerto Rico, y más rica, tenía sólo $23.000^{2}$. $\mathrm{El}$ análisis de Labra tenía ciertas deficiencias, la más evidente es el hecho de que la propiedad de la tierra se hallaba altamente concentrada a lo largo de los llanos costeros donde era común la coexistencia del latifundio azucarero

* Ponencia presentada en el 103 Congreso anual de la American Historical Association. Sesión patrocinada por la Society for Spanish and Portuguese Studies y por la Conference on Latin American History, Cincinnati, 1988.

1 P. N. Chiles (1975), pp. 42 y 97.

2 R. M. de Labra (1870). 
con el minifundio de subsistencia. Aun así, en ese gran grupo de propietarios muchos estaban aparentemente desinteresados en cambiar el statu quo, a pesar de la negativa de España a iniciar reformas.

Este ensayo explora las conexiones entre estructura socioeconómica y comportamiento político a fines del siglo xix en Puerto Rico. Existían consideraciones económicas cruciales en la negativa de la colonia a unirse a las regiones cubanas en rebelión y evitar una confrontación violenta con España.

Durante las últimas tres décadas del siglo xIx, Puerto Rico pasó paulatinamente del azúcar al café como producto principal de exportación. Los cafetales se expandieron y la producción aumentó, como resultado de las preferencias de los empresarios en invertir en el café en vez del altamente rentable negocio azucarero. La tendencia ascendente de los precios del café en el mercado internacional contrastaba con la tendencia descendente de los del azúcar. Mientras que en Cuba, a principios de la década de los noventa, los capitalistas optaron por enfrentar la caída de los precios del azúcar con la ampliación de los cultivos de caña y la transformación tecnológica (que requería grandes inversiones y rendía grandes ganancias), en Puerto Rico la producción de azúcar declinó y la modernización del equipo de procesamiento se hizo selectivamente. En los primeros años de la década de los noventa, los valores de las exportaciones del café puertorriqueño casi duplicaron a los del azúcar. En los años siguientes, los triplicaron ${ }^{3}$.

Hacia fines de siglo un gran porcentaje del café puertorriqueño se producía en fincas medianas o pequeñas. Esto ocurría especialmente en la región de Utuado. El trabajo de Fernando Picó muestra que en 1894, el 69 por 100 del café de la región se producía en 647 fincas de 100 cuerdas o menos. El restante 31 por 100 se producía en 14 haciendas más grandes ${ }^{4}$. Para Lares, Laird Bergad encontró que en 1897 fincas de entre 21 y 100 cuerdas de café constituian más de la mitad de los sembradíos. La región de Yauco fue la excepción. El trabajo de Bergad revela también que allí, en 1899, las haciendas con más de 100 cuerdas en café producían más de la mitad de la cosecha ${ }^{5}$.

Los caficultores enviaban la producción a los establecimientos comerciales de los pueblos del interior o directamente a los comerciantes de los puertos, quienes poseían el equipo necesario para secar, descascarar, pilar y clasificar los granos de café. Las firmas comerciales de los puertos acumularon grandes y estables fortunas a partir del negocio del café. Adelantaban a crédito dinero y mercancias (refacción) a los caficultores o a los comerciantes del interior

${ }^{3}$ E. Colón (1930), p. 289.

4. Ficó (1981), p. 41. Una cuerda $=0,97$ acre.

s. W. Bergad (1983), pp. 178 y 187. 
La tierra era una garantía valiosa que los caficultores pudieron usar al comenzar plantaciones de café o al renovar las viejas. Los comerciantes portuarios concentraban varias funciones, además de las estrictamente relacionadas con el café -importaciones, transporte, banca, transferencias monetarias- y establecieron relaciones duraderas y lucrativas con los deudores.

El café puertorriqueño se vendía a España, Cuba y a varios puertos europeos directamente o vía Ing'aterra. Entre 1890 y 1895 los países europeos (Francia, Alemania, Italia, Austria...) compraban un promedio anual de 42 por 100 de la cosecha de la isla. Durante ese período Cuba y España compraron un 35 y un 23 por 100 , respectivamente ${ }^{6}$.

Una característica de la economía del café puertorriqueño hacia fines del siglo xIX, de acuerdo con Nathan Koenig, fue que no "compensó económicamente por el descenso de la producción de azúcar especialmente en la cantidad de empleos que proveyó»? ${ }^{7}$ El café requería menos trabajadores a jornal, y tal vez siguió siendo menos lucrativo que el azúcar. La economía del café no parece haber logrado atraer la creciente población del interior hacia el mercado de trabajo, menos aún a la población desempleada en la costa debido a la crisis del azúcar. En el interior, los que no tenían trabajo permanente tendían a quedarse, al menos parte del año, en la propiedad de la familia. Entre los pequeños agricultores los costos de producción eran mínimos y había mecanismos de sobrevivencia tales como la siembra de cultivos de subsistencia y el no registrar las propiedades para evitar la ejecución hipotecaria y los impuestos ${ }^{8}$.

Se puede cuestionar todavía por qué la élite comercial de Puerto Rico no tuvo éxito en acelerar más el desarrollo de la economía del café. Muchos caficultores y comerciantes eran inmigrantes españoles (especialmente mallorquines) que tendían a regresar a la península. Caficultores y comerciantes liquidaban todas, o parte, de sus participaciones en la colonia según regresaban a España, con las consecuentes transferencias de capitales de la colonia a la metrópoli.

Mi trabajo se basa en el estudio de una firma mercantil mallorquina del puerto de Arecibo, en la costa norte de Puerto Rico. El caso de la firma Roses y Cía., de Arecibo, clarifica aspectos pobremente entendidos de la economía del café. El resultado - desarrollo más lento, pobreza extendida y escasez de capital, en oposición a crecimiento rápido y explotación intensareflejó probablemente las preferencias de las élites económicas y gobernantes del país. En muchos aspectos el sistema fue el resultado de la política con-

6 L. W. Bergad (1983), Apéndice.

N. Koening (1953), p. 28. La traducción es mía.

${ }^{8}$ F. Picó (1981), pp. 85.95; Boletín Mercantil, 22 octubre 1893; Revista de Ag:icu'tura, Industria y Comercio, 9 noviembre 1885, p. 163. 
figurada en Madrid con la aquiescencia de líderes coloniales de todas las convicciones políticas. Todo esto es, sin duda, pertinente para entender las preferencias políticas de muchos puertorriqueños en la década de los noventa.

\section{El caso de Roses y Cía., de Arecibo}

Después de la quiebra de la firma vasca Ulanga y Cía. en 1860, ninguna otra firma había logrado absorber porciones tan grandes del comercio regional de Arecibo hasta Roses y Cía., en la década de los ochenta. A diferencia de Ulanga y Cía., que había basado su imperio comercial en el azúcar, la firma Roses convirtió el café en su principal fuente de ganancia. Aunque al principio (en los 1860) los hermanos Roses eran sólo pulperos o comerciantes de mediana importancia que participaban en escala reducida en el azúcar, estaban siempre estrechamente relacionados con las redes comerciales de café de la región. Esto no es sorprendente, ya que los catalanes y los mallorquines desempeñaron un papel fundamental en la comercialización del café de mediados de siglo promovida entonces por participaciones catalanas con base en Aguadilla, otro puerto del norte. Miguel Roses, fundador de la firma, se emparentó con una familia catalana de Utuado. Su suegro era el representante en Utuado de una de las más grandes firmas catalanas de Aguadilla exportadoras de café ${ }^{9}$.

Miguel Roses fue a Puerto Rico muy joven desde su pueblo natal, Soller, en Mallorca. Trabajó de grumete en una goleta que hacía viajes regulares a Puerto Rico. Luego estuvo empleado en un restaurante mallorquín en San Juan. En 1861 se estableció en Arecibo como socio menor de una pulpería mallorquina. Durante los años siguientes, Roses invirtió con toda seguridad viejos ahorros y nuevas ganancias en el capital de la tienda e hizo venir desde Mallorca a su hermano Antonio como su socio ${ }^{10}$.

La expansión de Roses y Cía. siguió el patrón común entre los comerciantes españoles. Una cerrada red comercial de vínculos étnicos y de parentesco tomó forma durante las décadas del setenta y ochenta. Se estableció una colonia mallorquina en estrecha relación con Roses y Cía. Las tiendas mallorquinas rurales y urbanas compraban suministros en el almacén general. Roses y Cía. era el socio capitalista en esas nuevas firmas, controlando hasta un 50 por 100 del capital ${ }^{11}$.

- Para más detalles sobre la casa Roses y Cía., véase A. Cubano (1988). También, Archivo General de Puerto Rico (AGPR), Protocolo Notarial de Pedro Vidal, Arecibo, 17 agosto 1870 , p. 180.

${ }_{10}$ AGPR, Protocolo Notarial de Francisco de Torres, 18 mayo 1861, p. 167; Protocolo Notarial de Miguel Gandia, 12 mayo 1868, p. 128.

"Libros de Roses y Cía., Cuentas Corrientes 1878-86; AGPR, Protocolo Notarial de 
La red comercial creada entre 1876 y 1886 permitió a Roses y Cía. absorber una gran parte del comercio y de los servicios en Arecibo y Utuado. Esto, a su vez, permitió a la firma establecer relaciones comerciales directas con firmas extranjeras $y$, de este modo, penetrar la élite comercial de importación y exportación en gran escala. En 1886 obtuvo una línea de crédito de Frederick Huth y Cía., de Londres, lo que constituyó un logro de crucial importancia para la firma mallorquina ${ }^{12}$. En medio de una devaluación monetaria que forzaba al cierre de sus tiendas a muchos importadores, el volumen comercial de Roses y Cía. crecía de forma tal que le permitía establecer contactos directos en Londres y abrir una cuenta en libras esterlinas para el café embarcado a Inglaterra y a otros puertos europeos. Las ventas de café a Frederick Huth y Cía. aumentaron a principios de la década del noventa. De allí en adelante, se establecieron muchos otros contactos internacionales mientras se multiplicaban las cuentas extranjeras de Roses y Cía.

\section{La politica estatal y el comercio del café}

Mientras en Cuba se fortalecía la economía del azúcar, lo que permitía adoptar el patrón oro, en Puerto Rico los caficultores y comerciantes dependían de la devaluación monetaria para poder hacer sus pagos locales. Para hacer frente a la devaluación internacional de la moneda de más uso en Puerto Rico, el peso de plata mejicano, el gobierno colonial había fijado un valor más alto a esa moneda. De este modo, la isla atrajo más pesos mejicanos devaluados en el exterior. La devaluación comenzó a principios de la década del ochenta con un aumento en los tipos de cambio de un 12-14 por 100 . En adelante continuó sin control hasta la década del noventa ${ }^{13}$.

La política monetaria permitió una serie de transacciones lucrativas a los comerciantes portuarios que recibían moneda extranjera, depositada en sus cuentas en el exterior en pago de las mercancías exportadas. Es reveladora la cuenta «Banca» que aparece en el libro mayor de Roses y Cía. En esta cuenta se registraban las ganancias obtenidas de los negocios cambiarios, es decir, de la venta de moneda extranjera a los importadores y a otras personas de la población. También se registraban las ganancias obtenidas al hacer importaciones oportunas cuando los tipos de cambio estaban más altos, aparentemente antes del tiempo de cosecha. Esto parece haber sucedido del siguiente

José $A$. de la Torre, 31 julio 1879 , p. $716 ; 17$ julio 1880 , p. 1325; 17 septiembre 1884, p. $1016 ; 12$ julio 1898 , doc. 175 .

${ }_{12}$ Libros de Roses y Cía., Cuentas Corrientes 1886-89.

${ }^{13}$ Boletin Mercantil, 3 mayo 1895; Revista de Agricultura, Industria y Comercio, 9 agosto 1885 , p. 92. 
modo. Si Roses y Cía. enviaba a Londres un cargamento de café valorado en 1.000 libras esterlinas, cuando el tipo de cambio estaba a 7 pesos por libra esterlina, la entrada de 7 pesos aparecía en la columna pesos en el lado «debe» en la cuenta del comprador extranjero. Presuntamente, la casa comercial había pagado a los caficultores según correspondía. Algún tiempo después, la firma pagaba por un embarque de arroz valorado también en 1.000 libras en Londres. Sin embargo, el tipo de cambio estaba entonces a 8 pesos por libra. Los 8 pesos correspondientes aparecían en la columna pesos en el lado «haber» en la cuenta del comerciante extranjero. Presumiblemente, el precio del arroz se fijaba en conformidad con la moneda local y se vendía a otros comerciantes, a los detallistas y a los consumidores. Así que Roses y Cía. tenía que entrar en las cuentas extranjeras lo que llamaba «beneficio por diferencia en cambio" para poder lograr un balance de las columnas «debe» y «haber». En nuestro caso hipotético, esta ganancia sería de 1.000 pesos. Roses y Cía. transfería esos beneficios a su cuenta «Banca».

La élite mercantil de los puertos logró acumular impresionantes fortunas. Dirigía redes comerciales étnicas y de parentesco y respaldaba con capital los negocios en pequeña o mediana escala (al por menor tanto como al por mayor) que permanecieron bajo la protección de la firma principal. Los comerciantes nativos marginados de estas redes comerciales (importadores independientes y detallistas), al carecer de capital para la refacción en gran escala $y$, por tal razón, tampoco tener acceso a un producto de exportación ni a los pagos en moneda extranjera, no podian competir. Tenían que pagar por sus importaciones en plata mejicana devaluada (recibida de sus clientes urbanos) o comprar letras de cambio en moneda extranjera a sus competidores.

Es indudable que muchos caficultores participaron de la prosperidad de la primera mitad de la década de los noventa. Los beneficios del alza en los precios del café durante esos años favorecieron, sin duda, tanto a quienes se dedicaban al mercadeo como a la producción del café. Parece claro también que la moneda devaluada y la política estatal fueron la base de un lucrativo comercio de exportación de café.

Sin embargo, el sistema se basaba en los precios altos de artículos de primera necesidad, por no mencionar el equipo y maquinaria agrícola importados. Los altos costos de producción desalentaron la expansión en gran escala de los cafetales. Fue realmente excepcional que los terratenientes de Yauco llevaran a cabo costosos incrementos de los cafetales conjuntamente con la formación de haciendas bien equipadas. Comprar tierras y sembrar nuevos árboles era una empresa extremadamente costosa.

Por el contrario, el alto consumo de bienes importados, hasta entonces fuera de alcance, se convirtió probablemente en una inversión atractiva para los terratenientes que en determinado momento se encontraban libres de 
deudas. Entre los más prósperos tenía una prioridad mayor el consumo conspicuo, la construcción de casas y los viajes.

Una parte de las ganancias de los inmigrantes dedicados a la comercialización del café se transfería a España en forma de capital de inversión, fondos de retiro o ayuda familiar. Las ganancias de Roses y Cía. obtenidas de las ventas de café en los puertos españoles se quedaban en España. La firma vendía a las personas del pueblo y a los terratenientes varios miles de pesos todos los años en forma de giros para ser enviados a, y pagados en, varias ciudades de la península. Estos eran documentos de cambio girados contra los depósitos de la firma en España. Por ejemplo, la cuenta de E. Sainz e hijos en Madrid registra sobre 9.000 pesos vendidos en giros entre septiembre de 1893 y marzo de 1894 . Estas eran pequeñas ventas hechas a muchos compradores; había más de cuarenta entradas, algunas que incluían varios compradores («giros a varios») ${ }^{14}$.

Las firmas portuarias con cuentas en bancos extranjeros fueron las responsables del deterioro más significativo de la reserva de capital de inversión de la colonia. Realizaron grandes transferencias de fondos a España, muchas veces directamente desde sus depósitos en Londres. Los miembros de Roses y Cía. que se retiraban comenzaron a hacer transferencias importantes en 1892. Tras la muerte del socio fundador, Miguel Roses, su viuda, la hija de un comerciante catalán en Puerto Rico, se trasladó a Barcelona. Entre 1892 y 1893 recibió un total de 71.096 pesos de la firma, seguidos de un total de 32.667 en 1894 y 91.468 en 1895. De forma similar, la cuenta del otro socio fundador, Antonio Roses, revela importantes transferencias de ganancias a España. Un total de 38.304 pesos se enviaron en 1893, seguidos de 65.633 en 1894 y 72.714 en 1895 . El total de transferencias de $1893-95$ sobrepasó los 380.000 pesos ${ }^{15}$.

A pesar de las grandes transferencias de dinero, las inversiones en la colonia no cesaron. Roses y Cía. continuó las operaciones de exportación y hasta se involucró en la diversificación económica en empresas tales como el establecimiento de una fábrica de jabón en 1894 o el proyecto de construcción de un sistema ferroviario para el interior ${ }^{16}$.

Aunque la firma no participó en el cultivo del café en gran escala, continuó proveyendo dinero en efectivo y mercancía a crédito. Las cuentas de los caficultores deudores eran periódicamente renovables y con frecuencia el balance del deudor se transfería a un nuevo dueño. Las deudas subsistían durante años y el interés se cargaba con regularidad. Los caficultores que

1" Libros de Roses y Cia., Mayor 1894, p. 44.

${ }^{15}$ Libros de Roses y Cía., Mayor 1892-93, pp. 180, 333, 533; Mayor 1894, pp. 55, 455, 684; Mayor 1895, pp. 50, 246, 573.

${ }^{16} \mathrm{~J}$. Blanch (1894), pp. 34-39. 
trataban de ponerse al día en los pagos parciales vencidos de la deuda tenían que permitir que se acumularan las nuevas deudas de refacción. Sin embargo, en el contexto del aumento de los precios del café, los agricultores lograban cumplir con sus obligaciones y algunos estaban libres de deudas ${ }^{17}$. Muchos de estos medianos y grandes agricultores que negociaban directamente y con éxito con la firma comercial portuaria eran, a su vez, los dirigentes de una red comercial de dependencia por endeudamiento a la que estaban atados muchos otros pequeños agricultores, aparceros y jornaleros. La tendencia ascendente de los precios del café atenuó el conflicto entre los agricultores endeudados y los comerciantes.

Los precios del café empezaron a mostrar una leve tendencia descendente desde 1895-1896. Además, la guerra de independencia de Cuba que empezó en 1895 produjo una disminución de las exportaciones de café a esa isla ${ }^{18}$. Los comerciantes de los puertos, como Roses y Cía., pudieron compensar la caída de las ganancias del café en 1897 con las ganancias crecientes del comercio del azúcar con Estados Unidos, mercado que se hizo más accesible por el descenso de la producción azucarera cubana ${ }^{19}$. De allí en adelante, el interior cafetalero entró en crisis.

Hasta 1895-96 la propiedad de la tierra y los patrones de mercadeo en el interior cafetalero de Puerto Rico, al igual que la política monetaria, nutrieron a la acaudalada élite comercial inclinada a dejar en el extranjero una parte importante de sus ganancias líquidas. El régimen español de fines del siglo XIX descansaba en estas transferencias de capital al Banco de España, al Crédito Balear y a varias otras firmas. Más aún, la colonia con su economía pobremente capitalizada, sus modos de vida rurales (que los coetáneos contrastaban con los modos refinados de la élite en los centros urbanos de Cuba), que carecía de establecimientos para estudios universitarios y de varias otras instituciones que caracterizaban el modo de vida metropolitano, no era posible que se convirtiera en la residencia permanente de la élite comercial y sus familias.

A pesar de sus resentimientos respecto de la élite mercantil española, los terratenientes y comerciantes puertorriqueños se abstuvieron de la acción revolucionaria. Si los terratenientes movilizaban a los pobres de la isla para que se rebelaran contra España, las perspectivas futuras eran que faltarian los medios para controlar o compensar a la población movilizada. En el contexto de una clara percepción del crecimiento económico aletargado se temía una

$"$ Se encuentra evidencia abundante de esto en las cuentas de los caficultores que llenan una gran cantidad de páginas en los Libros de Rose's y Cía. de 1892 a 1895.

"L. Bergad (1983), p. 171; Balanzas Mercantiles de Pucrto Rico (1890-1897); Boletin Mercantil, 21 febrero 1896.

19 Véanse las cuentas de ganancias de Libros de Roses y Cía. 1895-96. 
gran revuelta social. No faltaban opiniones más optimistas, pero permanecían aisladas e incapaces de promover el movimiento independentista puertorriqueño.

Más aún, hasta 1897 los caficultores y comerciantes de Puerto Rico dependian del gobierno de Madrid para preservar el acceso al mercado cubano. Las importaciones de café puertorriqueño en Cuba hacían más difícil la recuperación de la economía del café en las provincias del este y se podía esperar un movimiento cubano para proteger la producción nacional ${ }^{20}$. Por tal razón, en el conflicto cubano-español, muchos puertorriqueños se inclinaban a permanecer del lado de España. Las relaciones pacíficas con España eran esenciales para muchos caficultores.

En resumen, mientras los terratenientes de las provincias orientales de Cuba y el liderato rebelde de 1895 se sentían seguros del futuro de la economía cubana, los terratenientes y líderes políticos de Puerto Rico, abrumados por la inseguridad económica y los miedos sociales, se mantenían lejos del tono revolucionario y la insurrección.

\section{BIBLIOGRAFIA}

Balanzas Mercantiles de Puerto Rico (1890-1897), San Juan, Intendencia General de Hacienda.

BeRGAD, Laird W. (1983): Coffee and the Growth of Agrarian Capitalism in Nineteenth Century Puerto Rico, Princeton, Princeton University Press.

Blanch, José (1894): Directorio comercial e industrial de la isla de Puerto Rico para 1894, Mayagüez, Tip. de La Correspondencia.

Colón, Edmundo (1930): Datos sobre la agricultura en Puerto Rico antes de 1898, San Juan, Tip. Cantero Fernández, Inc.

Cubano, Astrid (1988): Trade and Politics in Nineteentb Centry Puerto Rico, Princeton (tesis de doctorado inédita).

Chiles, Paul Nelson (1975): The Puerto Rican Press Reaction to the United States, 1888. 1898, Nueva York, Arno Press.

KoEnIG, Nathan (1953): Comprebensive Agricultural Program for Puerto Rico, Washington, D. C., U. S. Department of Agriculture in cooperation with the Commonwealth of Puerto Rico.

Labra, Rafael María (1870): La cuestión de Puerto Rico, Madrid, Imp. de J. Noguera.

Picó, Fernando (1981): Amargo café: los pequeños y medianos caficullores de Utuado en la segunda mitad del siglo XIX, Río Piedras, Huracán.

${ }^{20}$ Boletin Mercantil, 21 febrero 1896 y 5 enero 1898. 